\title{
STORM EARLY WARNING SYSTEM AS A LAST PLUG-IN OF A REGIONAL OPERATIONAL OCEANOGRAPHY SYSTEM: THE CASE OF THE GULF OF CADIZ
}

\author{
Plomaritis, T.A. ${ }^{1}$, Benavente, J. ${ }^{1}$ Del Río, L. ${ }^{1}$ Reyes, $E^{2}$, Dastis, C. ${ }^{2}$ Gómez, M. ${ }^{3}$, Bruno, M. ${ }^{2}$
}

\begin{abstract}
The implementation of an Early Warning System for storm impacts in the urban beach of Cadiz is presented. The model train is described in detail together with the downscaling procedure. Emphasis is given on how the morphodynamic model receives the necessary information from the regional operational oceanography system specifically developed for the Gulf of Cadiz. The translation of the morphodynamic model output into useful information for the civil protection and other responsible authorities is provided based on the coastal state indicator approach. All the intermediate and final results are presented in a purpose-based on-line application.
\end{abstract}

Keywords: coastal-flooding; early warning systems; Gulf of Cadiz; morphodynamic modelling

\section{INTRODUCTION}

Marine storms are the natural events that can produce some of the greatest and most dramatic changes in coastal areas on a time scale of days. As the economic activities in the coastal zone (mainly recreational and urban development) notably increased during the second half of last century, a growing interest of the scientific community in understanding possible hazards on the coastal zone was developed. A number of large coastal disasters around the world, e.g. Hurricane Katrina (August 2005), windstorms Kyrill (January 2007), Klaus (January 2009) and Xynthia (February 2010), typhoon Yasin (February 2011) etc. have raised awareness on the vulnerability of the coastal areas due to natural extreme events and the associated losses of human life and properties (Alovisi et al., 2007; Gaztelumendi et al., 2011).

Nowadays, storm events are considered as the main driver for shoreline erosion, as well as an important cause of coastal flooding in low-lying areas. The ability to predict hazards associated to the above-mentioned phenomena can provide valuable information for civil protection and coastal management issues. Within the framework of the EU-funded project MICORE, early warning systems (EWS) for storm impacts on coastal zones were developed at nine sites in Europe (Ciavola et al., 2011).

The generation and propagation of storms takes place on macro- (ocean) and meso- (shelf) scales. In the Gulf of Cadiz the characteristics of the waves arriving to the coast are related to the atmospheric conditions prevailing over a large area of the North Atlantic Ocean during the previous days or weeks. Sea level variations are also affected by these atmospheric conditions as well as by meso-scale processes of coastal circulation over the continental shelf that results in coastal surges (Del Rio et al., 2012). Finally, the complexity of the coastal environment is generated by the interaction of a wide range of coastal hydro-morphodynamic processes that act on different temporal and spatial scales. During storm events, morphodynamic processes are accelerated, resulting in extreme erosion events that take place within few days (micro-scale) and can even affect the decadal trend of a stretch of coastline.

In the present work, the modelling procedure used for the case of Cadiz urban beach (SW Spain) will be presented as an example of an Early Warning System (EWS) suitable for a mesotidal sea with complex circulation patterns and a dissipative low-lying coast exposed to ocean waves. The existing operational oceanography systems are described together with the final morphodynamic application and the procedure for establishing the EWS.

\section{STUDY AREA}

The Gulf of Cadiz is the sub-basin that connects the Atlantic Ocean with the Mediterranean Sea through the Strait of Gibraltar. Its northern and southern boundaries are, respectively, the southwest coast of the Iberian Peninsula and the Atlantic coast of Morocco (Figure 1). As an Atlantic open coast, it is influenced by large-scale oceanic weather systems both in terms of precipitation, wind and large-

\footnotetext{
${ }^{1}$ Department of Earth Science, University of Cadiz, Campus Rio San Pedro, Puerto Real,11510, Spain.

2 Department of Applied Physics, University of Cadiz, Campus Rio San Pedro, Puerto Real,11510, Spain

${ }^{3}$ Puertos del Estado, Avda. del Partenón 10, Campo de las Naciones, Madrid, 28042,Spain.
} 
fetch waves. The storms generated by these systems are the main natural cause of coastal erosion in the area (Del Río et

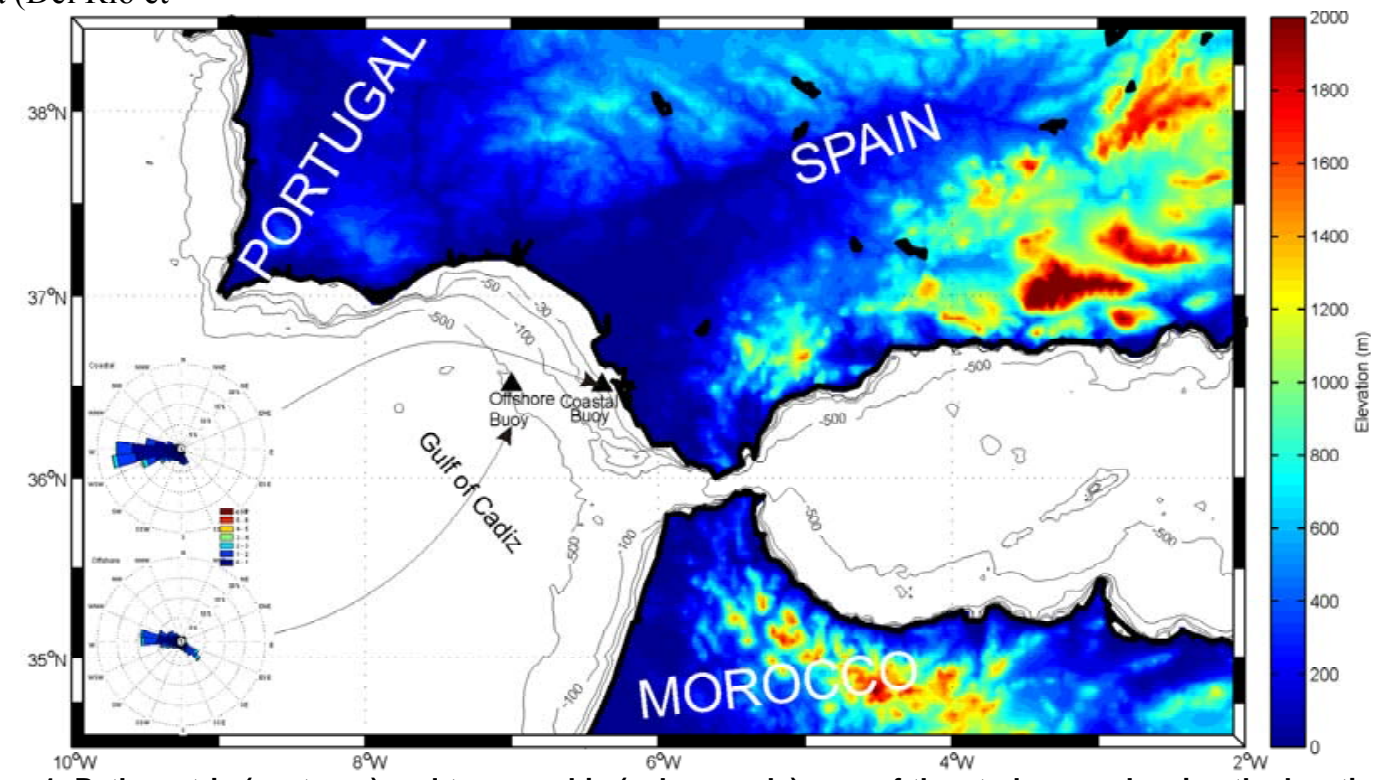

Figure 1. Bathymetric (contours) and topographic (colour scale) map of the study area showing the location of the offshore and coastal buoys of the Gulf of Cadiz together with their associated wave roses.

al., 2012). The orientation of the coastline and the local orographic characteristics of the southern Iberian Peninsula result in sheltering effects to the north component winds and funnelling effects to south and east component winds at the Strait of Gibraltar (Dorman et al., 1995). The above effects determine relatively different wind roses at the offshore and coastal buoys of the Gulf of Cadiz (Fig. 1). At the offshore areas, the contribution of the easterlies in the generation of local sea waves is observed, while it is prevented by shoreline orientation at the nearshore coastal buoys. Hence, the prevailing wave field at the coast is from WSW directions, with a yearly average significant wave height of $1 \mathrm{~m}$ comprised of both sea and swell, generating a predominant alongshore current toward the E and SE (Benavente et al., 2000).

In terms of tides, the area can be described as semidiurnal and mesotidal with a mean tidal range of $2.20 \mathrm{~m}$. The continental shelf has an average width of $50 \mathrm{~km}$ over the northern part of the Gulf and is significantly reduced close to the Strait of Gibraltar. The relatively small width of the continental shelf near the Strait of Gibraltar is responsible for the small presence of tidal higherharmonics and the reduced tide-surge interaction over the western region (Ratsimandresy et al., 2008). The surface circulation over the continental shelf is mainly wind-driven but it is also affected by local forcing mechanisms, such as the Guadalquivir River discharge (see García-Lafuente and Ruiz, 2007 for a review), and is subject to seasonal and inter-annual variations deeply related to the seasonal variability of the open sea circulation (Criado-Aldeanueva et al., 2009). Both circulation and wave climate are largely affected by the large-scale atmospheric patterns over the Atlantic Ocean, roughly represented by the NAO index (Criado-Aldeanueva et al., 2009; Plomaritis et al., in press).

\section{EARLY WARNING SYSTEM DEVELOPMENT}

An EWS is a systemic process for predicting impact of a phenomenon on a given area to facilitate the implementation of mitigation steps. In order to obtain an accurate prediction of the impact of a storm on the coastal environment that will lead to a reliable EWS, there is a need for correctly simulating the key processes that drive coastal erosion and flooding. This is a two-fold objective, since it implies the accurate simulation of the local scale storm processes that affect erosion, and the availability of high-quality boundary conditions of the incoming wave and sea level characteristics provided from larger operational models. Furthermore, all this has to be achieved within a time-frame of the forecast horizon in order to permit the authorities to respond accordingly.

The model train used for this purpose is presented in Fig. 2 and combines the operational oceanography frameworks of the University of Cadiz and that of the Spanish Port Authority (Puertos 
del Estado). This train is based on the use of various specific models and several nesting procedures in order to correctly simulate the hydrodynamic conditions in the Gulf of Cadiz.

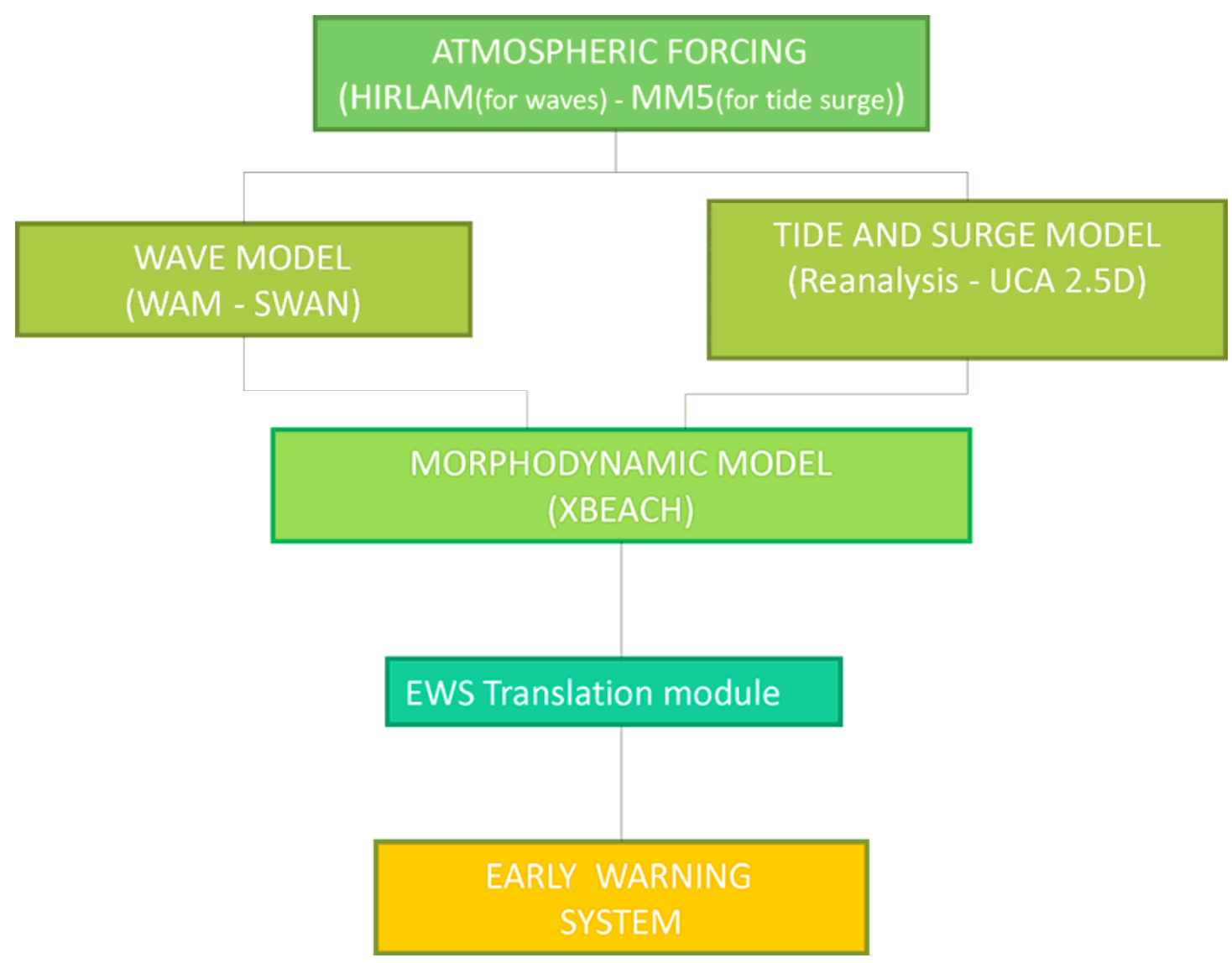

Figure 2. Schematic representation of the Operational Model and Early Warning System flow of information.

\section{OPERATIONAL SYSTEM DESCRIPTION}

\section{ATMOSPHERIC FORCING - MM5}

Atmospheric fields have been simulated using version 3.7.4 of the Fifth-Generation National Center for Atmospheric Research (NCAR) - Penn State Mesoscale Model (MM5) (Grell et al., 1994) implemented in Andalusia with maximum resolution reached in the Strait of Gibraltar.

The model configuration consists of a one-way active nested non-hydrostatic run with three grids whose resolutions are 30,10 and $3.3 \mathrm{~km}$, respectively (Figure 3), all of them with 35 vertical levels. The total number of computation points is $100 \times 80 \times 35$ for the coarse domain and $58 \times 43 \times 35$ for higher resolution grid domain. Hindcast experiments were carried out using the 6-h NCEP-GFS tropospheric analyses available on a global $0.5 \times 0.5^{\circ}$ grid for model initialization and boundary conditions. Results issued from this MM5 configuration have been successfully compared against observed atmospheric data, derived from Deep Sea Buoys observations located in the Gulf of Cadiz and Cape of Gata and from automatic weather stations for national and regional meteorological services (Reyes-Reyes et al., 2010).

Currently the weather forecast system runs daily in operational mode at the Applied Physics Department from the University of Cadiz, providing meteorological forecast for the Andalusia region up to 72-hours (Reyes-Reyes et al., 2007). The final user can access results in a friendly and quick mode by using the internet interface that has been built for this purpose (González et al., 2011). 


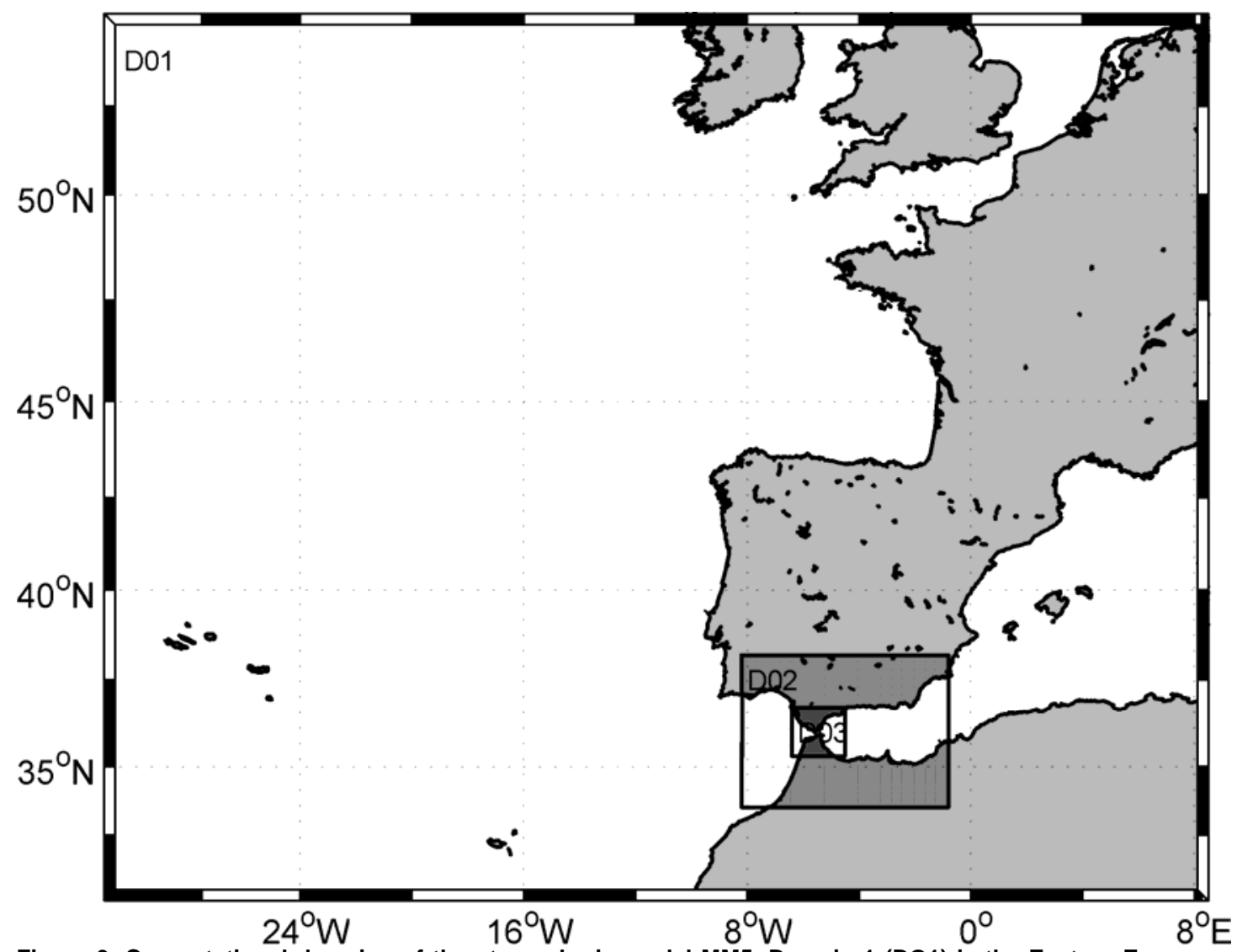

Figure 3. Computational domains of the atmospheric model MM5. Domain 1 (DO1) is the Eastern European domain and Domain 2 and 3 are the Andalusia (DO2) and Strait of Gibraltar (DO3) regions, respectively.

\section{TIDE -SURGE MODEL - UCA2.5}

The two-dimensional, two-layer, nonlinear, high-resolution, finite-difference UCA2.5D hydrodynamic model (Izquierdo et al., 2001) provides time-spatial fields of surface elevation, among other variables, as depth-averaged currents for the two layers and the depth of the MediterraneanAtlantic interface surface, for a domain over the Strait of Gibraltar, from the eastern part of Gulf of Cadiz to the western Alboran Sea, at $1 \mathrm{~km}$ average horizontal resolution.

The hydrodynamic model is driven by wind fields supplied by the MM5 atmospheric model at $10 \mathrm{~km}$ resolution. The prediction horizon is 72 hours, thus it is forced by the atmospheric model.

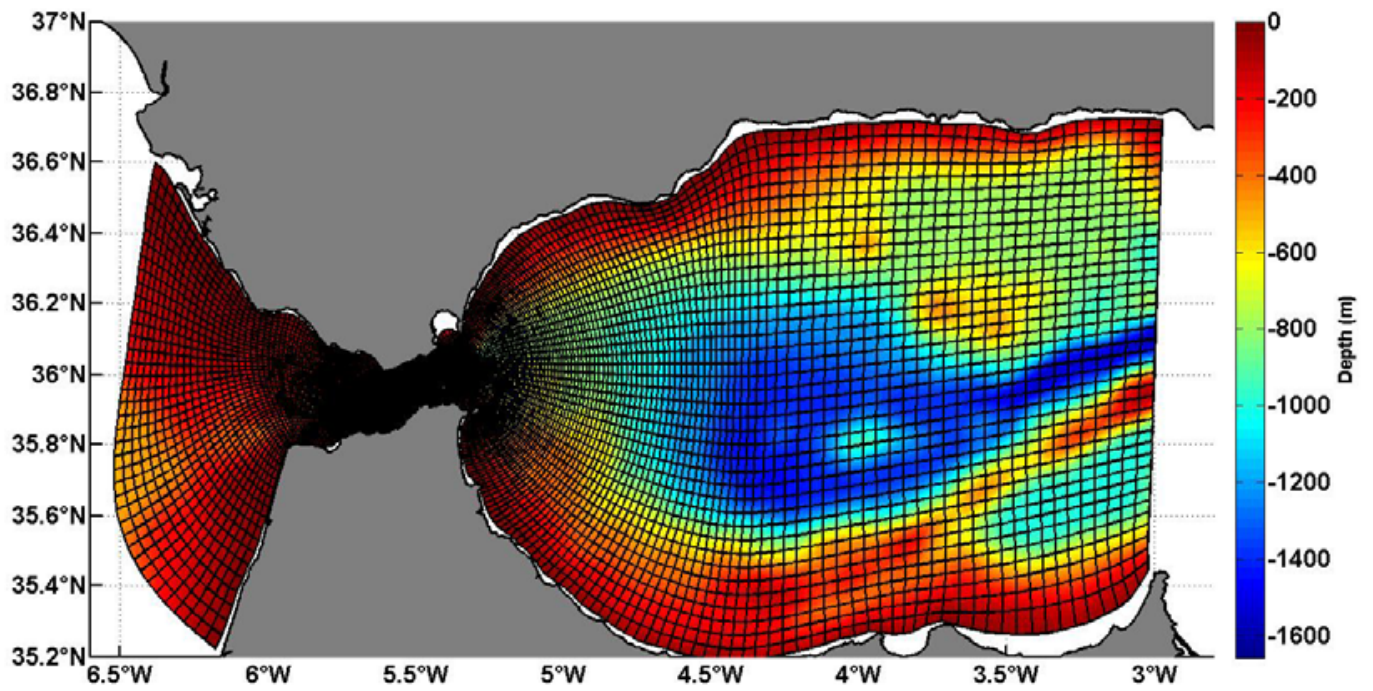

Figure 4. Computational domain of the hydrodynamic model UCA2.5D. The red dots correspond to the model's grid points. 


\section{WAVE MODEL - WAM-SWAN}

The wave prediction is provided by the operational oceanography services of Puertos del Estado. Wind forcing from the HIRLAM model ( 0.16 degrees) is used for a series of 4 nested WAM models that cover the North Atlantic open ocean area with a resolution of 1 and $1 / 2$ degree, respectively (Wave Domain 1 and 2), the continental shelf of the Iberian Peninsula (Wave Domain 3) with a resolution of a $1 / 4$ degree, and the Gulf of Cadiz with a resolution of 5 min (Wave Domain 4). The nesting is performed with the aim of better resolving the wave conditions (Figure 5 and Table 1). The models have two-way nesting scheme in order to obtain high resolution close to the Spanish narrow continental shelf without resolving to high resolution in the deep ocean. The model is being updated every 12 hours and has a forecast horizon of 72 hours. Model results are continuously verified with the buoy data collected along the Iberian Peninsula, showing a constant good agreement. Further details on the wave forecasting system for the Iberian Peninsula can be found in Gómez-Lahon and Albiach (2005).

\begin{tabular}{|l|l|c|c|c|}
\hline \multicolumn{6}{|l|}{ Table 1. Model Domains of the wave operational model WAM } \\
\hline Domain & 1 & 2 & 3 & 4 \\
\hline Hor. Resolution ( $\left.{ }^{\circ}\right)$ & 1 & $1 / 2$ & $1 / 4$ & $1 / 12$ \\
\hline Coupling & 1 way & 2 way & 2 way & 2 way \\
\hline Forecast Horizon (h) & 72 & 72 & 72 & 72 \\
\hline
\end{tabular}

Close to the major ports, a third generation model that solves the energy balance equation (SWAN) is nested to the ocean system described above. This nesting has a $200 \mathrm{~m}$ resolution and covers an area of $25 \times 25 \mathrm{~km}$ around the harbour. Boundary conditions are provided by the ocean model every 12 hours with the same forecast horizon as the ocean model (72 hours).

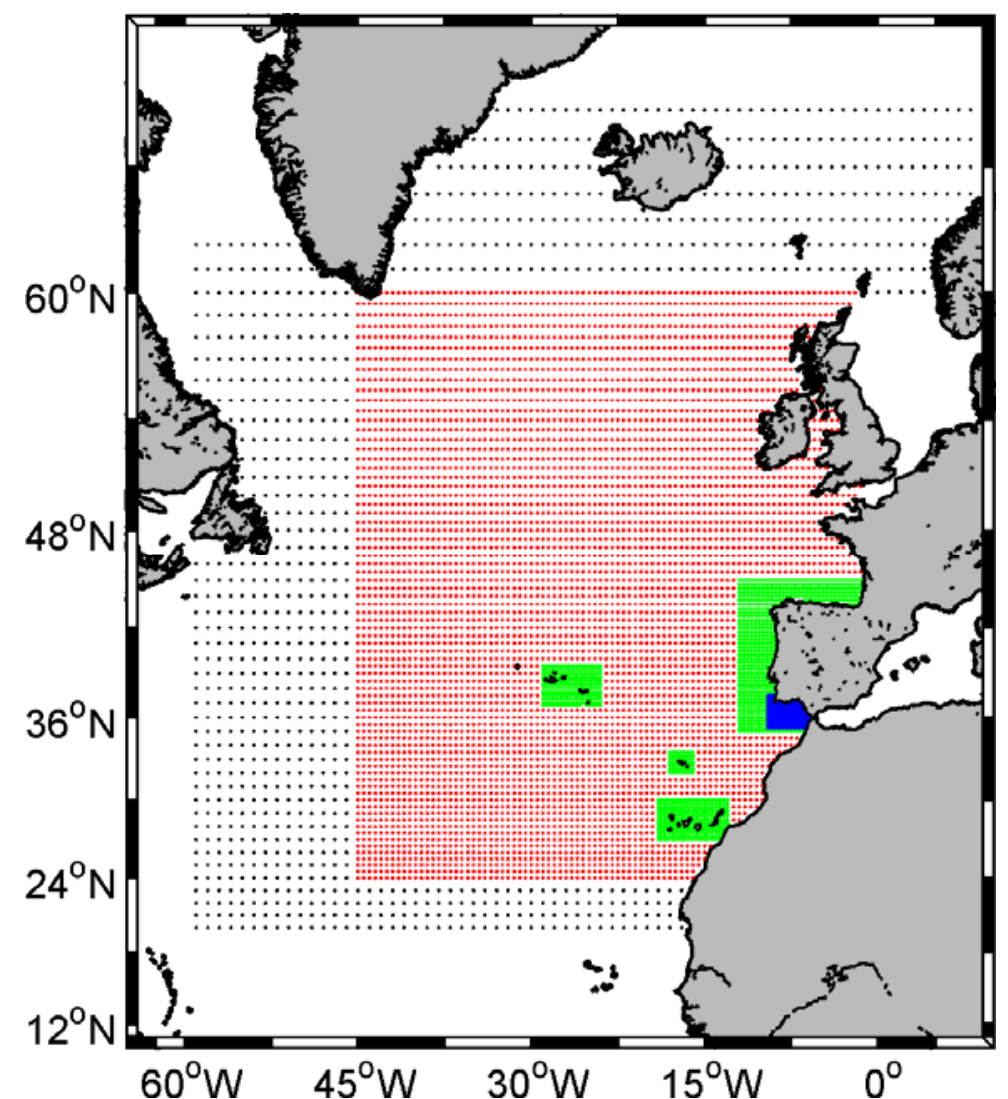

Figure 5. Computational grids for the Atlantic frame of the wave forecasting model WAM. The grid resolution is presented with different colors. Black for the 1 degree resolution; red for the $1 / 2$ degree resolution; green for the $1 / 4$ degree resolution and blue for the 1/12 degree resolution (Figure adapted from Gomez-Lahon and Albiach, 2005). 


\section{MORPHODYNAMIC MODEL - XBEACH}

The morphodynamic simulations are based on the XBEACH model. It is a purpose-built tool to simulate erosion due to storm events (Roelvink et al., 2009) under the different storm regimes described by Sallenger (2000), through the resolution of swash dynamics of wave groups. The model solves the coupled 2D horizontal equations for wave propagation, flow, sediment transport and bottom changes, for varying (spectral) wave and flow boundary conditions. In order to describe the wave groups and associated infragravity waves, the time-varying wave-action balance is solved in combination with a dissipation model (Roelvink, 1993) and a roller model (Stive and de Vriend, 1994) for the shoreward shift of the momentum. In terms of sediment transport, the Soulsby-van Rijn (Soulsby, 1997) formulation is used by averaging over short-waves but not over long-waves. The model has been tested for both $1 \mathrm{D}$ and $2 \mathrm{D}$ experiments under laboratory (e.g. van Thiel de Vries, 2009) and field conditions (e.g. McCall et al., 2010).

Due to the high computational demand of $\mathrm{XBEACH}$, the model is generally employed in relatively small areas in $1 \mathrm{D}$ or $2 \mathrm{D}$ mode. Wave boundary conditions are obtained from the wave operational model, which in turn is based on a nesting model approach of WAM and SWAN as described in the above section. Depending on the coastal settings, a possible addition of a detailed SWAN model forced with waves, currents and tides can be included prior to XBEACH; such addition is generally used in areas near the Strait of Gibraltar, where such processes are of great importance. Tide and surge conditions are obtained from the University of Cadiz operational oceanography system that is based on the forcing of the UCA2.5D circulation model (Izquierdo et al., 2001) with the atmospheric model (MM5) as described above.

In this paper, the XBEACH model is used on a $1 \mathrm{D}$ mode to simulate the hydrodynamic and morphodynamic evolution, on a 72-hour window, of three beach profiles at the urban beach of Cadiz. Boundary conditions are provided by the aforementioned regional operational model and consist of: (a) Tidal and surge elevations from the UCA2.5 forced by the MM5 model; tidal and/or wind-induced currents are not included because XBEACH is used in a 1D profile mode; (b) Wave boundary conditions are incorporated from a directional wave spectrum obtained from the WAM-SWAN downscaling procedure described above. A rectilinear non-equidistant coordinate system was used that extended for almost $5 \mathrm{~km}$ until a depth of $20 \mathrm{~m}$. The model has been calibrated and validated under various storm events that took place in the Gulf of Cadiz during the period 2008-2010 (Van Dongeren et al., 2009; Plomaritis et al., 2011). The model performance was measured using the Brier Skill Score (BSS) which relates the variance of the model with the variance of the observations. Under storm conditions with return period higher than 1 year, the BSS obtained was 0.69 .

\section{EWS TRANSLATION MODULE}

The last step of this procedure that transforms the model sequence into an EWS is the automatic analysis of the morphodynamic model output and the calculation of indexes, which can be directly used by the decision makers of regional and local authorities. In order to achieve this goal, a Storm Impact Indicator (SII) has to be initially identified and described. This SII should be useful for the enduser and achievable for the model to calculate, calibrate and validate.

Communication problems between scientist and end-users have been reported repeatedly and some of the main reasons have been identified by Van Koningsveld et al. (2005). In order to overcome this issue, the 'Frame of Reference' approach developed by Van Koningsveld and Mulder (2004) was used to help researchers convert the highly specialized model results in a practical decision context. This approach constitutes a methodology for facilitating the transfer of knowledge from research to management that has been previously used for the development of Coastal State Indicator (Van Koningsveld et al., 2005). The method focuses in the explicit definition of strategic and operational objectives through the identification of a quantitative state concept (QSC); a benchmarking procedure; an intervention procedure for coastal zone management and an evaluation procedure.

\section{CASE STUDY - CADIZ URBAN BEACH}

For the case of the Cadiz urban beach EWS, the selected SII was the 'Dry Beach Width'. This is a good proxy for both coastal flooding events and associated beach hazards that are related to the use of the beach. The above indicator was selected during a round table discussion that involved the local coastal and civil protection authorities as well as researchers from the University of Cadiz. The frame of reference established for the above SII is described in Table 2. Since the present modelling system 
has a prediction horizon of days (72 hours), the objectives and actions proposed by the SII have to be constrained to this time frame.

\begin{tabular}{|c|c|c|c|c|c|c|}
\hline $\begin{array}{l}\text { Strategic } \\
\text { Objective }\end{array}$ & $\begin{array}{l}\text { Operational } \\
\text { Objective }\end{array}$ & $\begin{array}{c}\text { QSC } \\
\text { Benchmarking }\end{array}$ & $\begin{array}{l}\text { Desired State } \\
\text { Benchmarking }\end{array}$ & Current State & $\begin{array}{l}\text { Intervention } \\
\text { Procedure }\end{array}$ & $\begin{array}{l}\text { Evaluation } \\
\text { Procedure }\end{array}$ \\
\hline $\begin{array}{l}\text { Guarante } \\
\text { e safe } \\
\text { use of } \\
\text { urban } \\
\text { coastal } \\
\text { front. }\end{array}$ & $\begin{array}{c}\text { Minimize } \\
\text { beach use } \\
\text { when a safe } \\
\text { exit corridor } \\
\text { (free of } \\
\text { runup) is } \\
\text { not } \\
\text { available. }\end{array}$ & $\begin{array}{l}\text { Distance } \\
\text { between the } \\
\text { exit corridors } \\
\text { (stairs at the } \\
\text { sea wall) and } \\
\text { maximum } \\
\text { runup values } \\
\text { calculated } \\
\text { from } \\
\text { XBEACH. }\end{array}$ & $\begin{array}{l}\text { Safe exit from } \\
\text { the beach is } \\
\text { guaranteed if } \\
\text { dry beach width } \\
\text { (DBW) is } \\
\text { higher than } 40 \\
\text { m. 'Medium } \\
\text { risk' exists } \\
\text { when the DBW } \\
\text { is between 40m } \\
\text { and } 10 \mathrm{~m} \text { and } \\
\text { 'high risk' when } \\
\text { it is smaller } \\
\text { than } 10 \mathrm{~m} .\end{array}$ & $\begin{array}{l}\text { The first } \\
\text { exceedance } \\
\text { of the } \\
\text { benchmark } \\
\text { level as } \\
\text { predicted by } \\
\text { XBEACH. }\end{array}$ & $\begin{array}{l}\text { 1. Surveillance of } \\
\text { hazardous area. } \\
\text { 2. Removal of } \\
\text { temporary } \\
\text { infrastructure } \\
\text { such as wooden } \\
\text { walkways. } \\
\text { 3. Installation of } \\
\text { small barriers to } \\
\text { protect the stairs } \\
\text { that give access } \\
\text { to beach facilities } \\
\text { located under the } \\
\text { seafront. } \\
\text { 4. Closure of } \\
\text { access to the } \\
\text { beach. }\end{array}$ & $\begin{array}{l}\text { Evaluation of } \\
\text { the model } \\
\text { results after the } \\
\text { storm in order } \\
\text { to estimate the } \\
\text { accuracy of the } \\
\text { warning }\end{array}$ \\
\hline
\end{tabular}

The accurate prediction of the maximum storm runup by the XBEACH model is of key importance for the utility of the above SII. Due to the morphological characteristics of the urban beach of Cadiz (i.e. fine sand, dissipative to ultra dissipative beach slopes), the maximum run-up during storm conditions is dominated by the long-wave bound with the wave group. This process is simulated by the time-varying wave-action balance equation with $\mathrm{XBEACH}$ with good results (Plomaritis et al., 2011). These results have been achieved due to: (i) the high-quality boundary conditions of wave and sea level that are provided from the two independent operational oceanography systems described above (Puertos del Estado and University of Cadiz, respectively), that are developed and run uninterruptedly for various years; and (ii) a good calibration and implementation of the XBEACH model at the urban beach of Cadiz that was undertaken within the EU project MICORE.

The model outputs used for the calculation of the SII are the instantaneous sea level height and the profile evolution computed by the XBEACH model close to the coast. The water level depth is extracted along the profile by comparing these two elevations. In order to avoid extreme run-up values of numerical source, a threshold of $7 \mathrm{~cm}$ has been used to define the thinnest layer of water. Following this, the width of the dry beach is calculated as the length of the last wet computational node from the start of the profile, which is chosen to be the seawall backing the urban beach of Cadiz (Figure 6).

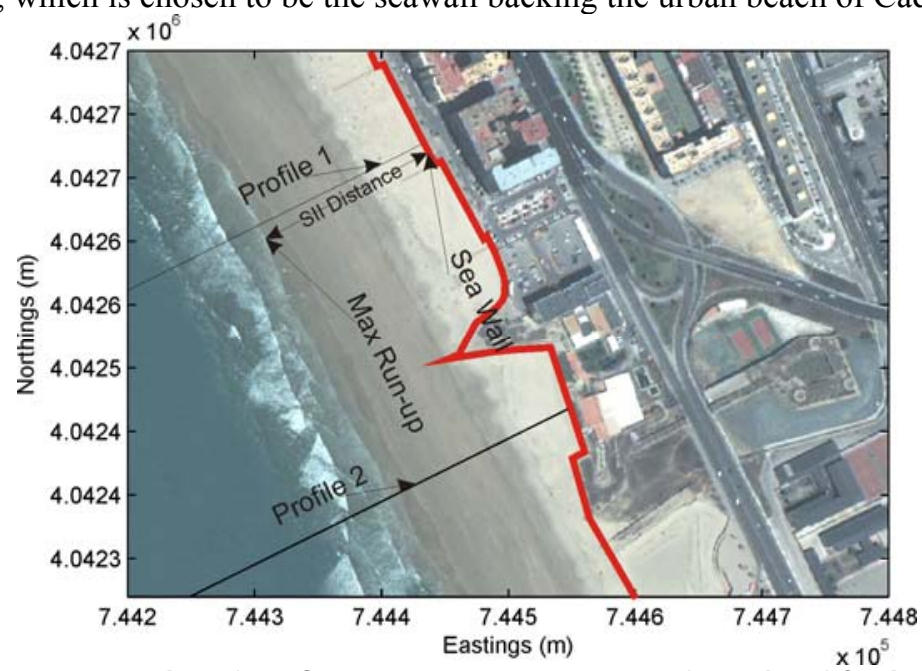

Figure 6. Schematic representation of the SII used at the urban beach of the city of Cadiz 
For a better understanding and interpretation of the SII prediction presented in the figures, the results are colour-coded following the 'Desired state benchmarking' (Table 2). Two graphics are produced and automatically uploaded to the website, one representing the highest risk for the following 3 days in a Google Maps application (Figure 7 left) and the other showing a more detailed daily timeevolution of the dry beach width (Figure 7 right). Currently, the EWS provides a forecast horizon of 72 hours for several 1D profiles over Cadiz beach. This information can be used for beach safety and flooding prevention purposes. The EWS has been running since June 2011; the prediction is updated on a daily basis and available through Internet (http://www2.uca.es/serv/micore/).
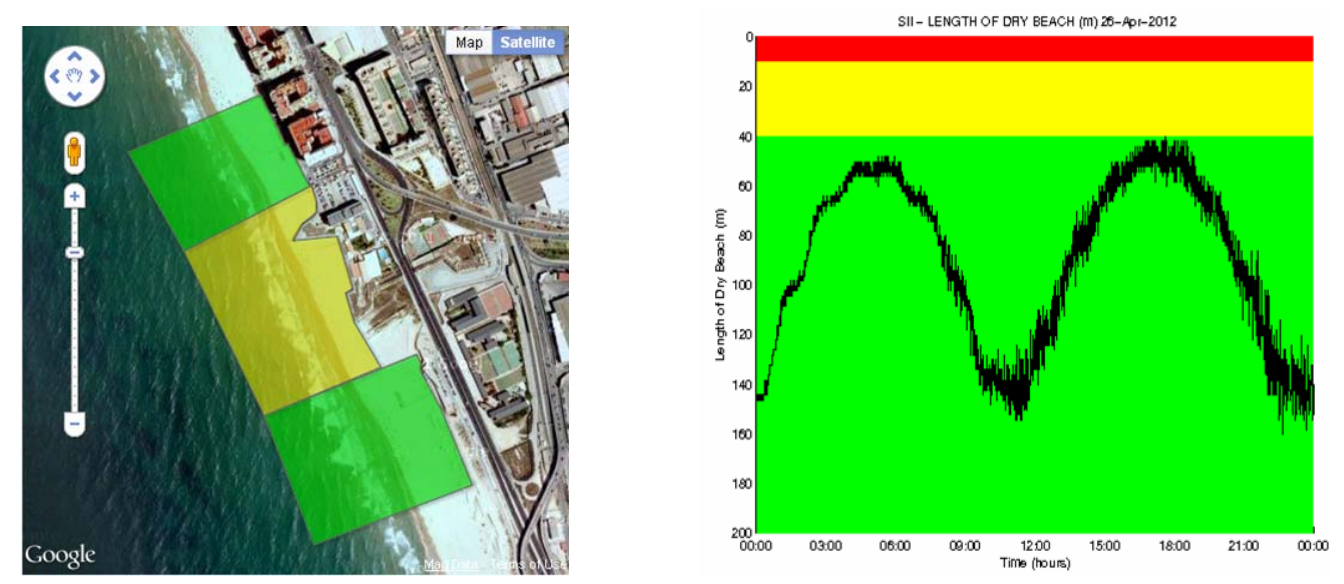

Figure 7. Left: the Interactive Google-Maps representation of the highest risk level for the next 72 hours. Right: the detailed prediction of the dry beach length for a period of 24 hours.

\section{CONCLUSIONS}

Establishing a fully operational EWS is a task that requires at least 5-10 years and the involvement of end-users at the local, national and international level (Ciavola et al., 2011). The scope of the MICORE project was to provide a prototype operational chain that could be used for the development of such a system together with the appropriate framework to translate the model output in information usable by the end-user. In the present work, the EWS developed for the urban beach of the city of Cadiz was presented. Although the EWS approach developed in the MICORE project was general, site-specific optimizations were often required for simulating the oceanographic and atmospheric conditions that affect the local morphological settings of the study sites. More specifically, the effect of the local wind on sea level and the open ocean waves on a relatively narrow continental shelf were resolved with a series of models nesting, while the computational demand of the morphodynamic modelling was addressed with $1 \mathrm{D}$ simulations.

The accuracy of the final morphodynamic model is greatly dependent on the quality of the boundary conditions and the model implementation. In the present case, the existence of two well established operational models especially developed for the Gulf of Cadiz proved of great importance, since they had already incorporated part of the downscaling efforts needed before the final morphodynamic model was set. It has to be mentioned that the use of open-source models was of vital importance both during the implementation and the operational phase, resulting in computational efficient codes suitable for on-line operational systems. The final EWS translation module also benefited from open-source codes for the data analysis and the on-line transfer of results to the web.

Finally, it must be noted that the SII are the base of the EWS and should be chosen according to the needs of the end-users, the local morphodynamic and oceanographic settings and the performance of the various models implicated. The use of the 'Frame of Reference' approach proved to be a useful tool towards establishing proper indicators.

\section{ACKNOWLEDGMENTS}

The authors gratefully acknowledge the EU Seventh Framework Program funding through the research project MICORE (grant agreement No. 202798). The local authorities are also acknowledged for their contribution to the process of establishing the storm impact indicators. 


\section{REFERENCES}

Alovisi, J., Souch, C. and Toothill, J., 2007. Windstorm Kyrill: A glimpse into the future? Catastrophe risk management.

Benavente, J., Gracia, F.J. and Lopez-Aguayo, F., 2000. Empirical model of morphodynamic beachface behaviour for low-energy mesotidal environments. Marine Geology, 167(3-4), 375390.

Ciavola, P., Ferreira, O., Haerens, P., Van Koningsveld, M. and Armaroli, C., 2011. Storm impacts along European coastlines. Part 2: lessons learned from the MICORE project. Environmental Science and Policy, 14(7), 924-933.

Criado-Aldeanueva, F., Garcia-Lafuente, J., Navarro, G. and Ruiz, J., 2009. Seasonal and interannual variability of the surface circulation in the eastern Gulf of Cadiz (SW Iberia). Journal of Geophysical Research-Oceans, 114, C01011, doi:10.1029/2008JC005069.

Del Rio, L., Plomaritis, T.A., Benavente, J., Valladares, M. and Ribera, P., 2012. Establishing storm thresholds for the Spanish Gulf of Cadiz coast. Geomorphology, 143-144, 13-23.

Dorman, C.E., Beardsley, R.C., and Limeburner, R., 1995. Winds in the strait of Gibraltar. Quarterly Journal of the Royal Meteorological Society, 121, 1903-1921.

García-Lafuente, J. and Ruiz, J., 2007. The Gulf of Cadiz pelagic ecosystem: A review. Progress in Oceanography, 74, 228-251.

Gaztelumendi, S., Egaña, J., Gelpi, I. R., Otxoa de Alda, K., Hernández, R. and Pierna, D., 2011. Windstorm XYNTHIA: Local effects and operational aspects in Basque Country case. 6th European Conference on Severe Storms (ECSS 2011), Palma de Mallorca, Balearic Islands, Spain.

Gómez Lahoz, M. and Carretero Albiach, J.C., 2005. Wave forecasting at the Spanish coasts. Journal of Atmospheric \& Ocean Science, 10(4), 389-405.

González, C.J., Reyes, E., Carmona, A., Megías, B., López, L., Vidal, J., Izquierdo, A. and Álvarez, O., 2011. Hydrodynamic modelling and operational oceanography for oil-spill events in the Andalusian Coast: a real case study during the Fedra accident (October 2008). MARTECH, Cádiz (Spain).

Grell, G., Dudhia, J., and Stauffe, D., 1994. A Description of the Fifth-Generation Penn State/NCAR Mesoscale Model (MM5). NCAR/TN-398+STR

Izquierdo, A., Tejedor, L., Sein, D.V., Backhaus, J.O., Brandt, P., Rubino, A. and Kagan, B.A., 2001. Control Variability and Internal Bore Evolution in the Strait of Gibraltar: A 2-D Two-layer model study. Estuarine, Coastal and Shelf Science, 53, 637-651.

Larson, M. and Kraus, N.C., 1995. Prediction of Cross-Shore Sediment Transport at Different Spatial and Temporal Scales. Marine Geology, 126(1-4), 111-127.

McCall, R.T., Van Thiel de Vries, J.S.M., Plant, N.G., Van Dongeren, A.R., Roelvink, J.A., Thompson, D.M., and Reniers, A.J.H.M., 2010. Two-dimensional time dependent hurricane overwash and erosion modeling at Santa Rosa Island. Coastal Engineering, 57(7), 668-683.

Plomaritis, T.A., Benavente, J., Laiz, I. and Del Rio, L. Storminess interannual variability and coastal hazards over the south-western Spanish coast: Links to large scale atmospheric forcing. Geomorphologie: relief, processus, environnement (in press).

Plomaritis, T.A., Del Rio, L. and Benavente, J., 2011. Validating storm threshold using a single Environmental Parameter: The case of Cadiz coast. Journal of Coastal Research, SI 64, 18761880 .

Ratsimandresy, A.W., Sotillo, M.G., Carretero Albiach, J.C., Alvarez Fanjul, E. and Hajji, H., 2008. A 44-year high-resolution ocean and atmospheric hindcast for the Mediterranean Basin developed within the HIPOCAS Project. Coastal Engineering, 55(11), 827-842.

Reyes Reyes, E., Izquierdo, A., Alvarez, O., Mejias, C., and Vinogradov, S., 2007. Wind field evaluation of the MM5 over the Strait of Gibraltar 20th-23rd August, 2004. $4^{a}$ Reunión de la Red Ibérica MM5. Aveiro (Portugal).

Reyes-Reyes, E., Bruno, M., Izquierdo, A. and Dastis, C., 2010. A forced ocean-atmosphere model to perform long-term hydrodynamic response induced by atmospheric forcing within the Strait of Gibraltar. $39^{\text {th }}$ CIESM Congress, Venice (Italy).

Roelvink, D., Reniers, A., van Dongeren, A., van Thiel de Vries, J., McCall, R., and Lescinski, J., 2009. Modeling storm impacts on beaches, dunes and barrier islands. Coastal Engineering, 56(1112), 1133-1152. 
Roelvink, J.A., 1993. Dissipation in random wave groups incident on a beach. Coastal Engineering, 19(1-2), 127-150.

Sallenger, A.H., 2000. Storm impact scale for barrier islands. Journal of Coastal Research, 16(3), 890895.

Soulsby, R.L., 1997. Dynamics of Marine Sands: A manual for practical applications. Thomas Telford, London, $249 \mathrm{pp}$.

Stive, M.J.F., de Vriend, H.J., 1994. Shear stresses and mean flow in shoaling and breaking waves. In: Edge, B.L. (Ed.), Proceedings of the Twenty-Fourth International Conference, ASCE, pp. 594608.

Van Dongeren, A., Bolle, A., Vousdoukas, M., Plomaritis, T., Eftimova, P., Williams, J., Armaroli, C., Idier, D., Van Geer, P., Van Thiel de Vries, J., Haerens, P., Taborda, R., Benavente, J., Trifonova, E., Ciavola, P., Balouin, Y., and Roelvink, D., 2009. MICORE: dune erosion and overwash model validation with data from nine European field sites. In: Proceedings of Coastal Dynamics 2009: Impacts of Human Activities on Dynamic Coastal Processes. pp. 1-15, doi:10.1142/9789814282475_0084.

van Koningsveld, M., Davidson, M.A. and Huntley, D.A., 2005. Matching science with coastal management needs: The search for appropriate coastal state indicators. Journal of Coastal Research, 21(3), 399-411.

Van Thiel de Vries, J.S.M., 2009. Dune erosion during storm surges, Delft University of Technology, Delft, The Netherlands, 202 pp. 